\title{
Mapeamento da ocorrência do Aedes aegypti na Região Nordeste de Anápolis (GO) em 2017
}

\section{Mapping the occurrence of Aedes aegypti at Eastern Region of Anapolis (GO) in 2017}

Rafaela Cristina Souza 1, Adriana Aparecida Silva 2, Divina Aparecida Leonel Lunas Lima ${ }^{3}$

\section{RESUMO}

Estudos demonstram que problemas endêmicos surgem devido à falta de controle do perímetro urbano, constituindo obstáculos à administração pública e gerando consequentes mazelas para a população. A expansão não planejada das cidades, a exemplo do que ocorre na região nordeste de Anápolis, tende a se relacionar com questões de saúde pública, pois promove a proliferação de criadouros de mosquitos que causam doenças como a dengue. Nesta região encontram-se bairros relativamente novos, como o Residencial Flor do Cerrado aprovado em 2012, com densidade populacional baixa e elevado número de lotes baldios $(37,95 \%$ de área ocupada) onde não foram notificados casos de dengue, além de bairros antigos, como o Recanto do Sol, criado em 1979, com $61,63 \%$ de sua área ocupada e registro de 34 casos confirmados de dengue. Os dados revelaram que nos bairros mais antigos e com menor número de lotes baldios estão concentradas as maiores quantidades de casos da doença, inferindo que a intervenção da prefeitura em áreas desocupadas tem sido eficiente, o que não acontece em relação aos lotes habitados.

Palavras-chave: Cartografia da Saúde. Dengue. Anápolis.

\section{ABSTRACT}

Studies show that the endemic problems arise due to the lack of control of the urban perimeter, constituting obstacles to public administration and generating consequent problems for the population. The unplanned expansion of the cities, as in the Northeast region of Anapolis, tend to public health issues, as it promotes the proliferation of mosquito breeding sites that cause diseases such as dengue. In this region are relatively new neighborhoods, such as Residencial Flor do Cerrado approved in 2012, with low population density and a high number of vacant lots (37.95\% of occupied area) where no dengue cases were reported, in addition to old neighborhoods, such as Recanto do Sol, created in 1979 , with $61.63 \%$ of its area occupied and 34 confirmed cases of dengue recorded. The data revealed that in the oldest neighborhoods and with the lowest number of vacant lots, the largest number of cases of the disease are concentrated, implying that the intervention of the city in unoccupied areas has been efficient, which does not happen in relation to the inhabited lots.

Keywords: Health Cartography. Dengue. Anápolis.
Mestra em Ciências Sociais e Humanidades pelo Programa de Pós-Graduação Stricto Sensu Territórios e Expressões Culturais do Cerrado da Universidade Estadual de Goiás (UEG), Anápolis, GO.

E-mail: rafaelaproj@gmail.com

2 Doutora em Geografia pela Universidade Federal de Goiás, docente do Programa de PósGraduação Stricto Sensu Territórios e Expressões Culturais do Cerrado da Universidade Estadual de Goiás (UEG), Anápolis, GO.

3 Doutora em Economia pela Universidade de Campinas (UNICAMP), docente do Programa de Pós-Graduação Stricto Sensu Territórios e Expressões Culturais do Cerrado da Universidade Estadual de Goiás (UEG), Anápolis, GO. 


\section{INTRODUÇAOO}

Hoje no Brasil a dengue é considerada uma endemia, dado os números alarmantes de pessoas acometidas pela doença (POLONI, 2013). Diversos fatores facilitaram a propagação desta doença nos países tropicais e subtropicais, tais como: o rápido crescimento demográfico, associado à intensa e desordenada urbanização, inadequada infraestrutura urbana, o aumento da produção de resíduos não orgânicos, além da ineficiência das ações de saúde preventiva. No que tange a questões relacionadas a problemas de infraestrutura, são exemplos: ausência de asfalto, rede de esgoto, coleta e descarte incorreto de resíduos sólidos, fatores que facilitam a proliferação de vetores como o Aedes aegypti, que transmite além da dengue, outras doenças como a febre amarela, a chikungunya e a zika (MENDONÇA et al., 2009).

A ocorrência da dengue tem sido frequente na cidade de Anápolis/Goiás, onde todos os anos são registrados casos graves da doença. Em 2016 foram 15.767 o número de casos registrados, em 2017 este número foi de 3.685 casos, e em 2018, até o mês de setembro, os números já indicavam 2.965 casos registrados de pessoas contaminadas (SUS, 2018). Ainda que os números demonstrem uma queda no índice de contaminação da população, passando de 4\% em 2016 para 1\% em 2017, não deixa de ser preocupante dado o histórico e a gravidade da doença.

Com uma população de 385.520 habitantes (SUS, 2020), sendo grande parte advinda da migração, pessoas que vêm principalmente do nordeste e norte do país em busca de emprego junto ao Distrito Agroindustrial de Anápolis (DAIA) e outras indústrias espalhadas pela cidade, Anápolis está em constante crescimento. Tal fato tem como reflexo o aumento no número de bairros e de construções habitacionais, algumas situadas nas regiões mais afastadas da parte central do município, em geral bairros mais pobres e com valor agregado menor, que não são alcançados por políticas públicas. Em decorrência deste crescimento rápido e desordenado, regiões são negligenciadas em termos de infraestrutura e saúde pública.

Este estudo se apoia na abordagem teórica da Geografia da Saúde, por meio da qual é possível pensar a cidade enquanto um ambiente formado por elementos do meio físico, social e econômico, os quais podem estar associados à questão da distribuição regional das doenças (CASTRO, 1957). Buscando contribuir com a discussão acerca da relação entre os fatores causais e a distribuição das ocorrências de dengue, o presente artigo apresenta o olhar da espacialização, tendo como área de estudo a região nordeste 
da cidade de Anápolis no ano de 2017, com o objetivo de apresentar uma correlação entre os casos confirmados de dengue em relação às características dos bairros em termos de adensamento populacional e infraestrutura. O estudo foi realizado por meio de pesquisa em dados secundários disponibilizados principalmente pela Secretaria Municipal de Saúde (SEMUSA) do município analisado. Tais dados foram espacializados e analisados, conforme descrito no item metodologia.

A proliferação da dengue no Brasil tende a seguir um padrão de falta de infraestrutura e ausência de apoio por meio de ações públicas nos bairros como coleta de lixo e manutenção de áreas públicas. Espera-se neste estudo comprovar a hipótese que locais com alto índice de lotes não ocupados por residências e áreas públicas tenha uma maior incidência da doença, quando comparado com áreas ocupadas por residências ou áreas públicas.

Entende-se que doenças com as características da dengue, em termos de proliferações devido à falta de higiene e cuidados com o local de moradia e nos espaços urbanos públicos, podem levar a contaminações muito altas quando o poder público ausenta-se de suas funções nos bairros urbanos. Assim, buscamos contribuir com a discussão de ações para a melhoria das intervenções públicas para a garantia da saúde das populações urbanas.

\section{MATERIAIS E METODOS}

O município de Anápolis situado entre as coordenadas 16¹9'43" de latitude Sul e em 485'12" de longitude Oeste, na região central do Estado de Goiás, localiza-se entre duas metrópoles regionais brasileiras, sendo Goiânia a 57 km de distância e Brasília a 148 km. Possuindo mais de 100 anos de existência e uma população estimada em 387.520 habitantes (SUS, 2020), sua extensão atinge uma área de 933,156 km². A região nordeste da cidade, delimitada para este estudo, é uma área de expansão urbana composta pelos seguintes bairros: Jardim das Américas $3^{\underline{a}}$ etapa, Jardim dos Ipês, Loteamento Residencial América, Parque Residencial das Flores, Recanto do Sol, Residencial Araguaia, Residencial Flor do Cerrado 1a etapa, Residencial Portal do Cerrado, Residencial Vale do Sol e Vila Norte (figura 1). 


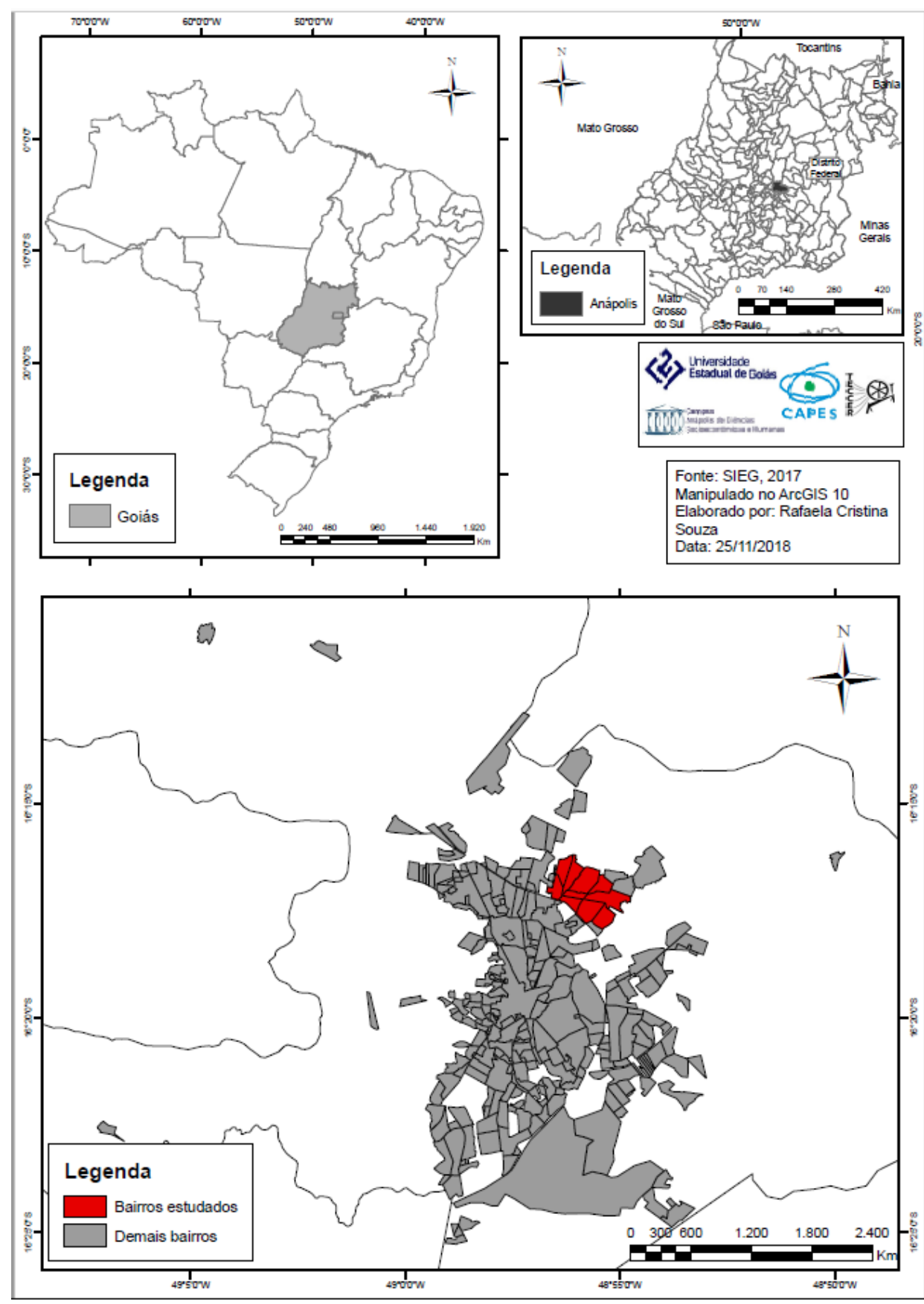

Figura 1. Mapa de localização dos bairros estudados em Anápolis (GO) no ano de 2017. Fonte: SIEG, 2017.

Nas etapas de execução da pesquisa envolveram a aquisição de dados na SEMUSA do município, juntamente com a Vigilância Epidemiológica, relativo ao número de casos confirmados de dengue por bairros de Anápolis no ano de 2017. A partir desses dados foram gerados gráficos de distribuição da doença durante os meses do ano, além de gerado o mapa da espacialização do número de casos de dengue por bairros, o qual foi 
elaborado com base em conceitos da cartografia temática, utilizando o modo de representação quantitativo, a implementação zonal e a variável visual cor, tendo como base o uso de cores em tons que variam do mais claro (para bairros com menor número de ocorrências) ao mais escuro (para bairros com maiores ocorrências). Os limites dos bairros foram representados por meio de vetores identificados no mapa da cidade de Anápolis - GO, utilizando o software ArcGIS 10.

Visando representar os fatores causais de ocorrência da doença organizamos em uma tabela as características de cada bairro, em relação ao tipo de ocupação, e correlacionamos com o número de casos notificados de dengue, zika e chikungunya. Além disso, foi elaborada uma carta imagem no software QGIS, tendo como base uma imagem de satélite de alta resolução disponível no Google Earth, na qual foram identificados e pontuados os lotes baldios, utilizando nesta identificação a variável forma, um ponto vermelho sobrepondo cada lote baldio. Informações sobre o histórico dos bairros e características de ocupação das áreas foram adquiridas junto ao trabalho publicado por Souza no ano de 2013.

A pesquisa foi realizada graças ao apoio financeiro da Coordenação de Aperfeiçoamento de Pessoal de Nível Superior (CAPES) e ao Programa de PósGraduação Stricto Sensu Territórios e Expressões Culturais do Cerrado (TECCER) da Universidade Estadual de Goiás. Não se fez necessário submeter à aprovação junto ao Comitê de Ética em Pesquisa (CEP), pois se tratou de uma pesquisa cujas informações foram obtidas em artigos já publicados e disponibilizados na literatura e na internet. Os dados foram obtidos na SEMUSA, sem abordagem direta aos residentes do município de Anápolis - GO.

\section{RESULTADOS E DISCUSSÃO}

O crescimento urbano sem planejamento e desprovido de acesso a políticas públicas e infraestrutura acarreta em problemas endêmicos (CZERESNIA, RIBEIRO, 2000; FLAUZINO, 2009; KAJIYA et al., 2017), conforme discutimos anteriormente. Para viabilizar a análise da relação entre o crescimento urbano e a dengue em Anápolis, selecionamos uma região com elevados índices de casos confirmados da doença, a região nordeste da cidade. O recorte temporal escolhido foi o ano de 2017, que, segundo dados do Mapa da Saúde do Estado de Goiás (SUS, 2020), nos meses iniciais deste ano 
houve um grande número de casos notificados de dengue (figura 2), relativo a um total de 3.046 casos em toda a cidade.

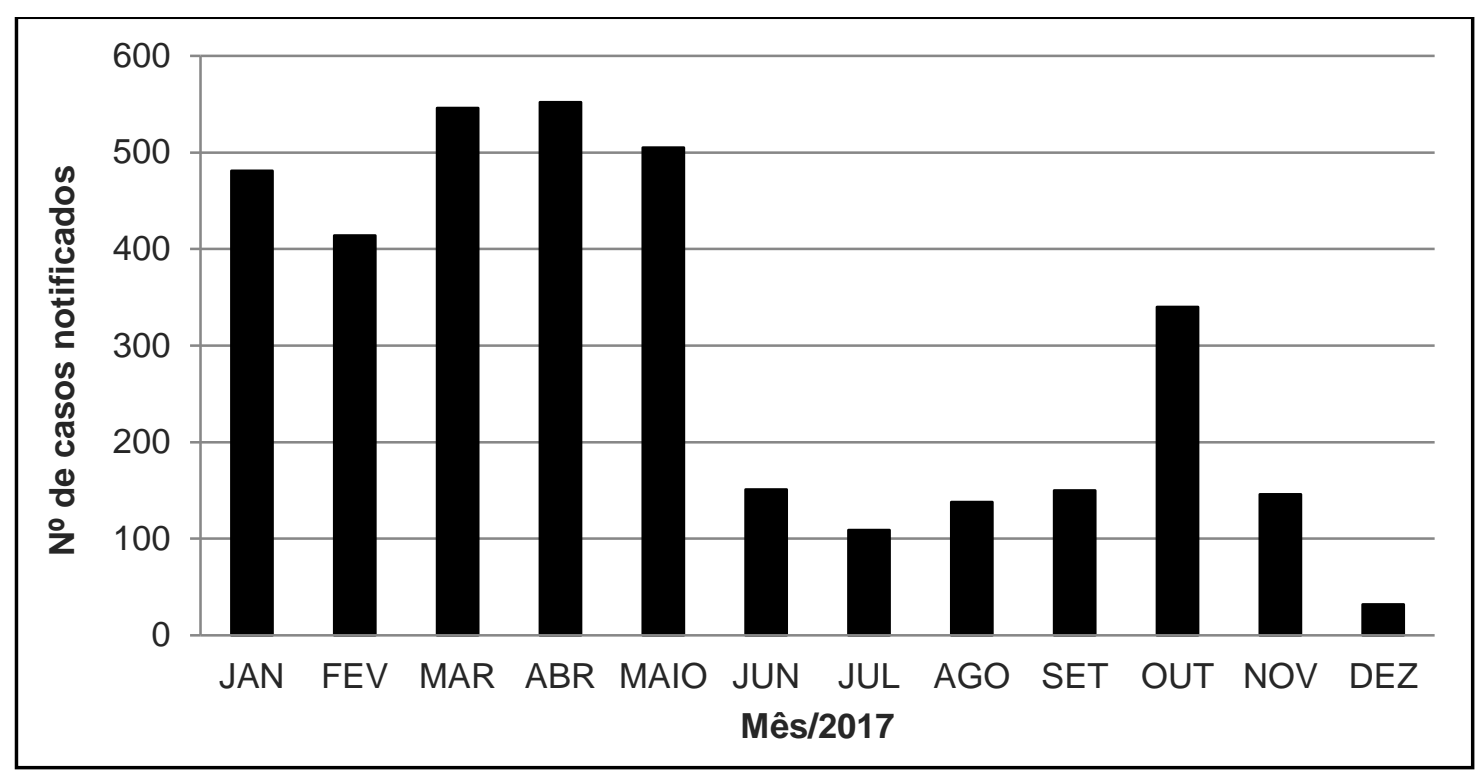

Figura 2. Número de casos notificados de Dengue em Anápolis (GO) no ano de 2017. Fonte: SUS, 2020.

A constituição da área nordeste da cidade de Anápolis data do final da década de 1970, tendo loteamentos aprovados desde 1979 até 2012. Esta área se encontra no entroncamento de duas importantes rodovias federais, sendo a BR-153 e a BR-414 (SOUZA, 2013). Trata-se de uma região importante do ponto de vista da incidência de casos notificados de dengue e de outras doenças transmitidas pelo mesmo vetor, uma vez que um de seus bairros, o Recanto do Sol, é o terceiro em número de casos confirmados de dengue na cidade de Anápolis (SEMUSA, 2018).

A figura 3 ilustra esta geografia da distribuição dos casos de dengue na região nordeste, a qual foi elaborada a partir dos dados obtidos junto a Vigilância Epidemiológica do município de Anápolis. Os dados permitiram saber ainda que, além do registro de 80 casos de dengue, foram confirmados 3 casos de zika na região estudada. Não houve registros de casos de chikungunya na região. 
DOI: 10.18605/2175-7275/cereus.v12n2p90-103 Revista Cereus 2020 Vol. 12. N.2
SOUZA, R. C.; SILVA, A. A.; LUNAS, D. A. L.

Mapeamento da ocorrência do Aedes aegypti na Região Nordeste de Anápolis (GO) em 2017.
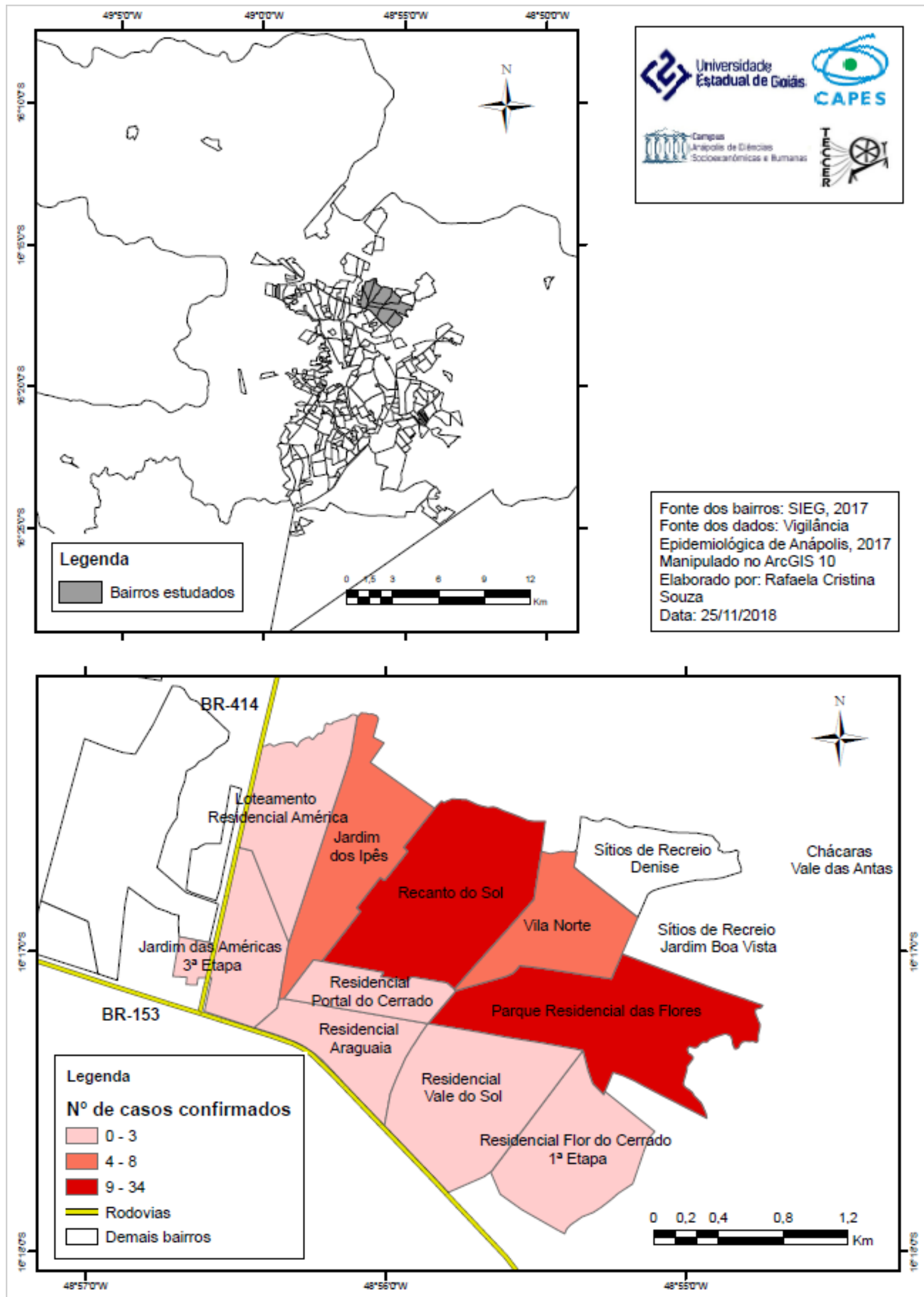

Figura 3. Mapa da dengue por bairros na Região Nordeste de Anápolis (GO) no ano de 2017. Fontes: SIEG, 2018; VIGILÂNCIA EPIDEMIOLÓGICA DE ANÁPOLIS, 2017. 
A região nordeste de Anápolis possui uma área em torno de $5.570 .000 \mathrm{~m}^{2}$ distribuídos entre 12 bairros, nos quais existem residências ainda por serem habitadas, lotes vagos e um grande aglomerado de moradores. Vamos caracterizar em seguida cada um dos bairros, apresentando o número de casos confirmados de dengue e outras doenças transmitidas pelo Aedes Aegypti, assim como as características gerais de ocupação (tabela 1).

Tabela 1: Características da ocupação e doenças confirmadas por bairros da Região Nordeste de Anápolis em 2017

\begin{tabular}{|c|c|c|c|c|c|}
\hline \multirow{2}{*}{ Bairros Região Nordeste } & \multirow{2}{*}{\multicolumn{2}{|c|}{$\begin{array}{c}\text { Características de ocupação em } \\
\% \text { da área do bairro }\end{array}$}} & \multicolumn{3}{|c|}{ № de casos confirmados em 2017} \\
\hline & & & Dengue & Zika & $\begin{array}{l}\text { Chikun- } \\
\text { gunya }\end{array}$ \\
\hline \multirow{5}{*}{ Jardim das Américas $3^{\text {a }}$ Etapa } & Lotes residenciais & $44,28 \%$ & \multirow{5}{*}{3} & \multirow{5}{*}{$\begin{array}{l}\text { Não houve } \\
\text { casos } \\
\text { confirmados }\end{array}$} & \multirow{32}{*}{$\begin{array}{l}\text { Não houve } \\
\text { casos } \\
\text { confirmados }\end{array}$} \\
\hline & Comércio & $2,35 \%$ & & & \\
\hline & Áreas de lazer & $8,47 \%$ & & & \\
\hline & Áreas públicas & $7,06 \%$ & & & \\
\hline & Logradouros & $22,68 \%$ & & & \\
\hline \multirow{3}{*}{ Jardim dos Ipês } & Lotes & $59,2 \%$ & \multirow{3}{*}{6} & \multirow{3}{*}{$\begin{array}{l}\text { Não houve } \\
\text { casos } \\
\text { confirmados }\end{array}$} & \\
\hline & Áreas públicas & $14,59 \%$ & & & \\
\hline & Logradouros & $23,08 \%$ & & & \\
\hline \multirow{4}{*}{$\begin{array}{l}\text { Loteamento Residencial } \\
\text { América }\end{array}$} & Lotes & $59,47 \%$ & \multirow{4}{*}{$\begin{array}{l}\text { Não houve } \\
\text { casos } \\
\text { confirmados }\end{array}$} & \multirow{4}{*}{1} & \\
\hline & Áreas de lazer & $8,02 \%$ & & & \\
\hline & Áreas públicas & $7,09 \%$ & & & \\
\hline & Logradouros & $25,43 \%$ & & & \\
\hline \multirow[b]{2}{*}{ Parque Residencial das Flores } & Lotes & * & \multirow[b]{2}{*}{24} & \multirow{2}{*}{$\begin{array}{c}\text { Não houve } \\
\text { casos } \\
\text { confirmados }\end{array}$} & \\
\hline & Comércio & * & & & \\
\hline \multirow{5}{*}{ Recanto do Sol } & Chácaras & $5,41 \%$ & \multirow{5}{*}{34} & \multirow[t]{5}{*}{ 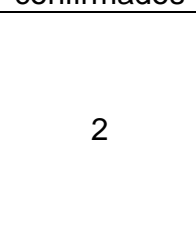 } & \\
\hline & Logradouros & $20,37 \%$ & & & \\
\hline & Áreas públicas & $9,38 \%$ & & & \\
\hline & Não loteado & $3,24 \%$ & & & \\
\hline & Outros & $61,63 \%$ & & & \\
\hline \multirow{4}{*}{ Residencial Araguaia } & Lotes & $61,11 \%$ & \multirow{4}{*}{3} & \multirow{4}{*}{$\begin{array}{l}\text { Não houve } \\
\text { casos } \\
\text { confirmados }\end{array}$} & \\
\hline & Áreas públicas & $14,28 \%$ & & & \\
\hline & Logradouros & $18,83 \%$ & & & \\
\hline & Área não edificante & $5,78 \%$ & & & \\
\hline \multirow{4}{*}{$\begin{array}{l}\text { Residencial Flor do Cerrado } 1^{\text {a }} \\
\text { Etapa }\end{array}$} & Lotes & $37,95 \%$ & \multirow{4}{*}{$\begin{array}{l}\text { Não houve } \\
\text { casos } \\
\text { confirmados }\end{array}$} & \multirow{4}{*}{$\begin{array}{l}\text { Não houve } \\
\text { casos } \\
\text { confirmados }\end{array}$} & \\
\hline & Logradouros & $27,03 \%$ & & & \\
\hline & Áreas públicas & $10,02 \%$ & & & \\
\hline & Áreas verdes & $5,07 \%$ & & & \\
\hline \multirow{3}{*}{ Residencial Portal do Cerrado } & Lotes residenciais & $64,7 \%$ & \multirow{3}{*}{$\begin{array}{l}\text { Não houve } \\
\text { casos } \\
\text { confirmados }\end{array}$} & \multirow{3}{*}{$\begin{array}{l}\text { Não houve } \\
\text { casos } \\
\text { confirmados }\end{array}$} & \\
\hline & Áreas públicas & $15,04 \%$ & & & \\
\hline & Logradouros & $20,26 \%$ & & & \\
\hline \multirow{2}{*}{ Residencial Vale do Sol } & Lotes residenciais & * & & Não houve & \\
\hline & Logradouros & * & 2 & $\begin{array}{c}\text { casos } \\
\text { confirmados }\end{array}$ & \\
\hline
\end{tabular}




\begin{tabular}{|c|c|c|c|c|}
\hline \multirow{4}{*}{ Vila Norte } & Lotes & $62,35 \%$ & \multirow{4}{*}{8} & \multirow{4}{*}{$\begin{array}{l}\text { Não houve } \\
\text { casos } \\
\text { confirmados }\end{array}$} \\
\hline & Áreas de lazer & $8,62 \%$ & & \\
\hline & Prédios públicos & $7,6 \%$ & & \\
\hline & Logradouros & $21,43 \%$ & & \\
\hline
\end{tabular}

Fontes: SOUZA, 2013; SEMUSA, 2018.

Legenda: * sem informação.

O bairro Recanto do Sol, com 34 casos confirmados de dengue e 2 casos confirmados de zika, é o primeiro bairro em número de casos de ocorrência da epidemia na região. Trata-se de um bairro antigo, que segundo Souza (2013) tem sua aprovação inicial em agosto de 1979, com área total de 944.083,21 m². Este bairro é composto por nove chácaras que totalizavam 51.066,61 $\mathrm{m}^{2}$, logradouros totalizados com área de 192.346,90 m², 88.551,21 $\mathrm{m}^{2}$ de área destinada a Prefeitura, 30.550,00 $\mathrm{m}^{2}$ de área não loteada e outras áreas com $581.797,90 \mathrm{~m}^{2}$.

Outro bairro com alto índice de casos confirmados de dengue é o Parque Residencial das Flores, com quantitativo de 24 casos. Esse bairro foi aprovado em 1983 e se refere a um bairro predominantemente residencial, com uma de suas ruas, a Avenida 25, muito importante para a região, pois nela se concentra os estabelecimentos comerciais. O loteamento da Vila Norte apresentou 8 casos confirmados de dengue no ano de 2017. Este bairro foi aprovado em 1982, quando compreendida uma área total de 411.400,00 m², sendo composto por 829 lotes que totalizavam $256.489,24 \mathrm{~m}^{2}$, além de reserva da área de lazer e praças com $35.444,90 \mathrm{~m}^{2}$. A área destinada a edifícios públicos é de $31.284,40 \mathrm{~m}^{2}$, sendo $88.181,46 \mathrm{~m}^{2}$ relativo a logradouros (SOUZA, 2013).

O bairro Jardim das Américas $3^{\underline{a}}$ Etapa, com 3 casos confirmados de dengue em 2017, teve aprovação do loteamento em 1983. Este bairro tem área total de 452.004,74 $\mathrm{m}^{2}$, representada por 620 lotes residenciais com total de $200.156,89 \mathrm{~m}^{2}, 30$ lotes comerciais representados por 10.600,56 m², área reservada ao lazer com 38.306,76 m², área reservada aos edifícios públicos com $31.891,82 \mathrm{~m}^{2}$, logradouros que totalizavam 102.509,71 m², além da faixa de domínio da BR-414 com $68.539 \mathrm{~m}^{2}$ (SOUZA, 2013).

No Loteamento Residencial América neste ano não foram registrados casos confirmados de dengue e apenas 1 caso confirmado de zika. Trata-se de um loteamento aprovado em 1983 com remanejamento em julho de 1992. Sua área total de 467.410,00 $\mathrm{m}^{2}$, se divide em 832 lotes totalizando $277.980,45 \mathrm{~m}^{2}$, área de lazer e praças que correspondem a $37.467,61 \mathrm{~m}^{2}$, área reservada a edifícios públicos que correspondia a $33.120,41 \mathrm{~m}^{2}$, e área reservada ao sistema viário com 118.841,53 m² (SOUZA, 2013). 
Os lotes do Residencial Araguaia foram aprovados no ano de 1999, com área total de $281.500 \mathrm{~m}^{2}$, que correspondia a 554 lotes com 172.019,95 m², três áreas públicas referentes a 40.200,79 $\mathrm{m}^{2}$, o sistema viário com 53.011,85 $\mathrm{m}^{2} \mathrm{e}$ a área não edificante com $16.267,43 \mathrm{~m}^{2}$. Já o Jardim dos Ipês, aprovado no mesmo ano, corresponde à uma área total de $529.746,59 \mathrm{~m}^{2}$, com 987 lotes totalizando $313.595,30 \mathrm{~m}^{2}, 12$ unidades reservadas a área pública referentes ao total de 77.267,15 m², 122.258,69 $\mathrm{m}^{2}$ reservados ao sistema viário, e 16.625,45 $\mathrm{m}^{2}$ correspondentes a área não edificante (SOUZA, 2013). Enquanto o Residencial Araguaia teve 3 casos confirmados de dengue, no Jardim dos Ipês foram 6 casos.

No século XXI, o bairro Residencial Portal do Cerrado teve a aprovação do loteamento em 2007, com área total de $187.001 \mathrm{~m}^{2}$, que correspondem a 381 lotes residenciais totalizando 120.989,61 $\mathrm{m}^{2}, 28.130,47 \mathrm{~m}^{2}$ reservados a áreas públicas, sistema viário com 37.880,92 $\mathrm{m}^{2}$ (SOUZA, 2013). Nele não tiveram ocorrências confirmadas de dengue ou das demais doenças apontadas.

Outro loteamento que pertence a esta região de Anápolis é o Residencial Vale do Sol, o qual foi aprovado em 2008, neste foram confirmados 2 casos de dengue em 2017. Já o Residencial Flor do Cerrado 1aㅡ Etapa, datando de 2012, com área total correspondente a 578.155,70 m², a área parcelada em lotes foi de 219.413,28 m² em 695 unidades, a área destinada ao sistema viário de 156.251,93 $\mathrm{m}^{2}$, a área destinada aos equipamentos públicos de 57.936,02 $\mathrm{m}^{2}$, e a área reservada para áreas verdes foi de 29.306,42 m² (SOUZA, 2013). Este último não teve caso confirmado de dengue em 2017.

$A$ análise dos dados revela que os bairros mais recentes possuem menor número de casos confirmados de dengue em comparação com bairros mais antigos. Além disso, pode-se observar que esses bairros também possuem menor área de ocupação, permitindo fazer a seguinte relação: bairros antigos, com maior habitação possui maior número de casos confirmados de dengue; enquanto que os bairros mais recentes e menos habitados possuem menor número de casos confirmados desta doença.

Foi identificado um grande número de lotes baldios nos bairros mais recentes, tais como Residencial Vale do Sol e Residencial Flor do Cerrado $1^{\text {a }}$ Etapa em comparação com bairros mais antigos, como o Parque Residencial das Flores e Recanto do Sol, conforme pode ser observado na figura 4. Tais lotes no geral possuem entulhos, resultantes do descarte indevido dos materiais de construção das proximidades e outros tipos de resíduos, no caso criadouros potenciais de mosquitos vetores. No entanto, ao contrário do esperado, não foram registrados os maiores números de casos confirmados 
DOI: 10.18605/2175-7275/cereus.v12n2p90-103

Revista Cereus

2020 Vol. 12. N.2
SOUZA, R. C.; SILVA, A. A.; LUNAS, D. A. L.

Mapeamento da ocorrência do Aedes aegypti na Região Nordeste de Anápolis (GO) em 2017.

da doença. Exemplo de bairro sem registro de caso confirmado de dengue e grande número de lotes baldios é o Residencial Flor do Cerrado $1^{\text {a }}$ etapa, o bairro mais recente na área da pesquisa, com baixa densidade populacional e ocupação por construções habitacionais.

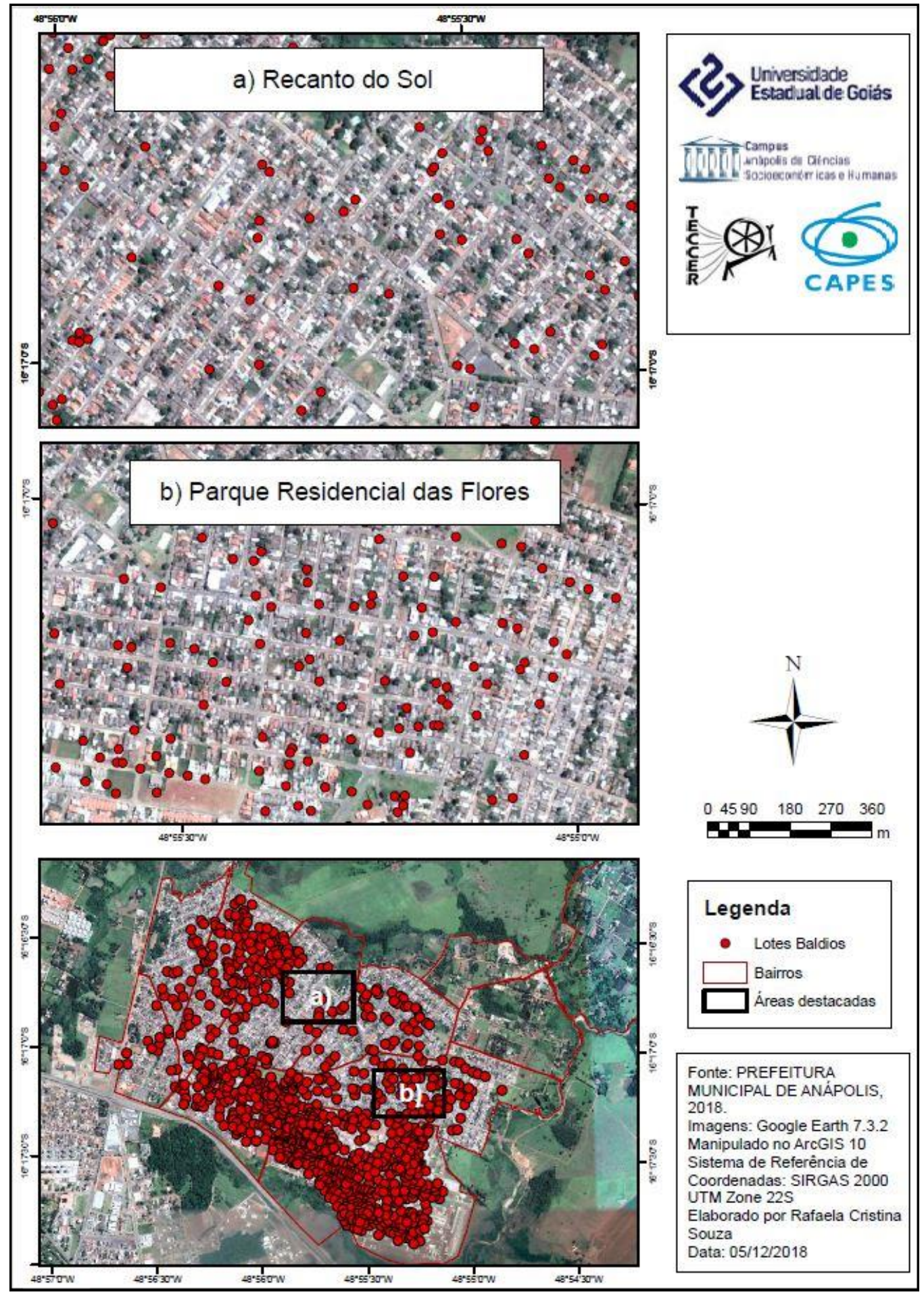

Figura 4. Carta imagem da Região Nordeste de Anápolis (GO) destacando os lotes baldios. Fonte: PREFEITURA MUNICIPAL DE ANÁPOLIS, 2018. 
Por outro lado, no bairro Recanto do Sol, onde se tem um número considerável de casos confirmados de dengue, também existem lotes baldios, ainda que em menor número, os quais são utilizados para o descarte incorreto de lixo residencial e entulho, o que certamente cria ambiente para proliferação do mosquito. Sendo um bairro densamente ocupado e urbanizado, considera-se que os principais criadouros do mosquito estão situados nas próprias residências e comércio, conforme estudo realizado por Catão (2011).

Os dados analisados nesta região indicam que há uma necessidade de mudança nas políticas públicas de intervenções, que devem privilegiar um trabalho de conscientização junto a sociedade Anapolina, pois somente assim haverá melhoria nas ações de combate à dengue no munícipio como um todo. Pelas características de proliferação da dengue na região analisada, entende-se que pode haver a mesma reprodução do que ocorre na região nordeste do município nos demais bairros da cidade.

\section{CONSIDERAÇÕES FINAIS}

A cartografia da dengue na região nordeste de Anápolis nos permitiu entender que existe uma relação entre número de pessoas contaminadas, densidade populacional e urbanização dos bairros. Foi observado que nos bairros mais recentes e pouco ocupados, tais como os que se situam em torno da BR-153 e da BR-414, não houve grande número de casos confirmados de dengue e outras doenças transmitidas pelo Aedes aegypti, mesmo considerando que nestes bairros o número de lotes baldios seja bastante representativo. Por outro lado, os bairros mais antigos e mais populosos e com menor número de lotes baldios, como o Recanto do Sol e o Parque Residencial das Flores, foram os que apresentaram maior número de pessoas acometidas pela dengue.

O mosquito Aedes aegypti busca colocar seus criadouros em vasos, calhas e recipientes com acúmulo de água parada, e por medidas de diagnóstico, um local que se apresenta com inúmeros focos desse mosquito teria maior risco em infectar pessoas próximas. Uma hipótese pensada foi a de que em ambientes com pouca limpeza como lotes baldios seriam focos do mosquito e, portanto, região de residência de maior parte dos contaminados. A pesquisa se mostrou reveladora, pois essa hipótese foi negada, acrescentando que os bairros com maior número de residentes e poucos lotes baldios foram os que apresentaram mais casos confirmados de dengue. 
Este resultado nos leva a considerar que a intervenção da SEMUSA, no sentido de eliminação de criadouros potenciais e prevenção da doença, tem sido eficiente em áreas desocupadas, onde o acesso é mais fácil. Já nos bairros com maior número de lotes habitados, onde o acesso é dificultado, devido à necessidade de autorização do morador, o trabalho preventivo não tem sido tão eficiente. Tal resultado, no entanto, não aponta para uma desobrigação do setor público em insistir e aumentar o trabalho preventivo dos agentes de saúde, pelo contrário, indicam que é essencial que seja feito um trabalho de conscientização com a população anapolina, para que a mesma se sinta efetivamente parte do processo de eliminação dos criadouros do mosquito, contribuindo assim com os agentes de saúde para a manutenção da saúde coletiva.

\section{REFERÉNCIAS}

CASTRO, Josué de. Geografia da Fome. São Paulo: Brasiliense, 1957.

CATÃO, Rafael de Castro. Dengue no Brasil: abordagem geográfica em escala nacional. Dissertação (Mestrado) - Universidade Estadual Paulista, 2011. Disponível em: <http://www.geosaude.com/resources/catao_rc_me_prud.pdf>. Acesso em: 20 nov. 2018.

CZERESNIA, Dina; RIBEIRO, Adriana Maria. O conceito de espaço em epidemiologia: uma interpretação histórica e epidemiológica. Cad. Saúde Pública, v. 16, n. 3, p. 595-605, 2000.

FLAUZINO, Regina Fernandes. Dengue, heterogeneidade e indicadores

socioambientais: particularidades da dinâmica da dengue em nível local. Tese (Doutorado) - Fundação Oswaldo Cruz, 2009. Disponível em: <https://www.arca.fiocruz.br/handle/icict/2546>. Acesso em: 18 maio 2020.

IBGE. Noções Básicas de Cartografia. Disponível em:

<https://ww2.ibge.gov.br/home/geociencias/cartografia/manual_nocoes/representacao.htm l>. Acesso em: 19 fev. 2018.

KAJIYA, Fernando Takeo; OLIVEIRA, Maria Aparecida; RIBEIRO, Helena. Dengue e saneamento na Região Metropolitana do Vale do Paraíba e Litoral Norte de São Paulo: aproximação a partir do geoprocessamento. In: RIBEIRO, Helena (Org.).

Geoprocessamento e Saúde: muito além de mapas. Barueri: Manole, 2017.

MENDONÇA, Francisco de Assis; SOUZA, Adilson Veiga e; DUTRA, Denecir de Almeida. Saúde Pública, Urbanização e Dengue no Brasil. Sociedade \& Natureza, v. 21, n. 3, p. 257-269, 2009.

POLONI, Telma Regina Ramos Silva. Estudo das características clínicas e laboratoriais da infecção pelo vírus da dengue em crianças atendidas em uma unidade de saúde no município de Ribeirão Preto, São Paulo. Tese (Doutorado) Universidade de São Paulo, 2013. Disponível em: 
<https://www.teses.usp.br/teses/disponiveis/60/60135/tde-24102013-084830/pt-br.php>. Acesso em: 18 maio 2020.

SISTEMA ESTADUAL DE GEOINFORMAÇÃO. Downloads. Disponível em: <http://www.sieg.go.gov.br/siegdownloads/>. Acesso em: 20 nov. 2018.

SISTEMA ÚNICO DE SAÚDE. Mapa da Saúde de Goiás: Casos Notificados de Dengue. Disponível em: <http://mapadasaude.saude.go.gov.br/\#s=2018-

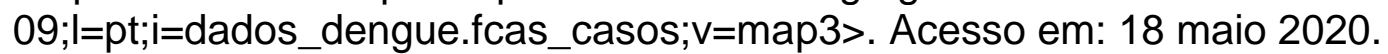

SOUZA, Bruno Augusto de. Descentralização e Eixos Comerciais em Anápolis (GO) de 2000 a 2012: a análise da área nordeste da cidade. Trabalho de conclusão de curso (Licenciatura) - Universidade Estadual de Goiás, 2013. 